\title{
Characteristics of stratospheric polar vortex fluctuations associated with sea ice variability in the Arctic winter
}

\author{
Jinju Kim ${ }^{1} \cdot$ Kwang-Yul Kim ${ }^{1}$
}

Received: 23 October 2019 / Accepted: 22 February 2020 / Published online: 4 March 2020

(C) The Author(s) 2020

\begin{abstract}
The leading two modes of winter (November-February) Arctic sea ice cover variability and their linkage to stratospheric polar vortex variations are analyzed based on the cyclostationary EOF techniques. The first mode represents an accelerating trend of Arctic sea ice decline associated with Arctic amplification, particularly in the Barents and Kara Seas. The second mode is associated with decadal-scale phase shifts of dipole sea ice anomalies in the North Atlantic caused by NAO circulation. The first two modes of sea ice variability represent respectively a forced climate change and internal variability, and result in temporally and spatially distinct stratospheric polar vortex weakening. Sea ice reduction in the Barents and Kara Seas for the first mode is linked to a stratospheric vortex weakening during mid January-late February. The second mode with the dipole structure of positive sea ice anomalies in the Barents and Greenland Seas and negative anomalies in the Hudson Bay and Labrador Sea is related to a stratospheric vortex weakening during December-early February. The spatial evolutionary structure of anomalous polar vortex also exhibits differences between the two modes. When stratospheric anomalies are fully developed, stratospheric vortex is shifted to Eurasia in the first mode and to Europe in the second mode.
\end{abstract}

\section{Introduction}

In recent decades, Arctic sea ice cover (SIC) has rapidly declined in association with the amplification of Arctic warming during winter (Cohen et al. 2014; Screen and Simmonds 2010; Serreze et al. 2009). Accordingly, many studies have focused on possible impacts of Arctic SIC reduction on Arctic and mid-latitude climates (Cohen et al. 2014; Kim and Son 2016; Kretschmer et al. 2016; Mori et al. 2014; Overland et al. 2011; Screen 2017a; Screen et al. 2018; Wu and Smith 2014). Interest in the effects of SIC on stratospheric variability is also increasing because stratospheric variation caused by SIC anomaly can spread downward and result in changes in tropospheric circulation. Several studies suggest that Arctic SIC reduction tends to weaken stratospheric polar vortex through an enhancement of upward

Electronic supplementary material The online version of this article (https://doi.org/10.1007/s00382-020-05191-9) contains supplementary material, which is available to authorized users.

Kwang-Yul Kim

kwang56@snu.ac.kr

1 School of Earth and Environmental Sciences, Seoul National University, Seoul 08826, Republic of Korea propagating planetary waves (Hoshi et al. 2017; Jaiser et al. 2016; Kim et al. 2014; Nakamura et al. 2015, 2016; Screen 2017a, b; Yang et al. 2016; Zhang et al. 2018). This SICrelated stratospheric change affects tropospheric circulation in the form of negative NAO/AO.

Change in Arctic SIC can be both a cause and a consequence of anomalous atmospheric circulation. AO/NAO, considered as an atmospheric response to a change in Arctic $\mathrm{SIC}$, is itself a major factor in regulating SIC variation $\mathrm{Hu}$ et al. 2002; Magnusdottir et al. 2004; Serreze et al. 2007; Strong and Magnusdottir 2011). Deser et al. (2000) found from 1958 to 1997 data that the leading mode of Arctic SIC variability, characterized by an east-west dipole structure in the North Atlantic and weak dipole anomalies in the Pacific, is related to the AO/NAO. However, Yang and Yuan (2014) argued that the leading pattern of SIC variability has changed since 1998 as evinced in the rapid SIC reduction in the Barents-Kara Seas. The observed patterns of Arctic SIC during 1979-2007 reflected an upward trend of atmospheric circulation such as Northern Annular mode (NAM) until 1993. Since then, an overall decline of Arctic SIC is clearly observed despite the downward trend of NAM (Deser and Teng 2008). A multi-century model study by Strong and Magnusdottir (2010) suggests that the leading mode of SIC variation in the Atlantic sector of the Arctic Sea may change 
from an NAO-related dipole pattern to an overall reduction pattern if the forced trend of SIC loss continues. In these studies, the two types of variations, corresponding to the overall loss of Arctic SIC and the dipole-like variation of Atlantic SIC, are found to play an important role in the total variability of Arctic SIC.

The change in the leading pattern of the Arctic SIC anomalies suggests that the dominant relationship between SIC and atmospheric circulation may also have changed. Although several studies discussed distinct natures of atmospheric responses to Arctic amplification and NAO/ AO (Cohen et al. 2018; Hassanzadeh and Kuang 2015; Kim and Son 2016; Mori et al. 2014; Screen 2017b), it is not yet clearly understood how stratospheric circulation differs between these two distinct surface conditions. If we distinguish the continuing sea-ice reduction in the Barents-Kara Seas as a forced climate change and the dipole sea-ice variation as a natural variability, clearer picture of stratospheric variability under different sea ice conditions can be achieved.

Previous studies have paid much attention to changes in stratospheric vortex strength in association with Arctic SIC variability in the context of zonal mean (Cohen et al. 2014; McKenna et al. 2018) or annular mode (Jaiser et al. 2016; Kim et al. 2014; Screen 2017a, b; Zhang et al. 2018). The geometric features of stratospheric vortex are also an integral part of understanding polar vortex variability (Lawrence and Manney 2018; Mitchell et al. 2013; Seviour et al. 2013). In this respect, Zhang et al. (2016) showed that stratospheric vortex continued to move toward Eurasia as Arctic SIC decreases. The spatio-temporal evolution of stratospheric disturbances, however, may change according to the SIC modes, and lead to distinct structural patterns of stratospheric vortex.

The objective of this study is to examine the major modes of winter SIC variability over 39 winters (1979/80-2017/18) and to understand their linkage with distinct stratospheric polar vortex variations. To better understand this linkage, spatio-temporal evolutions of stratospheric anomalies are analyzed in terms of intensity as well as horizontal and vertical structures. Changes in the wave interference conditions are also addressed in terms of vertical wave activity fluxes to delineate troposphere-stratosphere coupling in association with the leading SIC modes.

\section{Data and methods}

Data used in this study derive from the 1979-2018 ERA interim daily reanalysis product (Dee et al. 2011) at $1.5^{\circ} \times 1.5^{\circ}$ resolution for the Northern Hemisphere $\left(>30^{\circ}\right.$ N). Each winter consists of 120 days from November 1 to February 28; leap days are removed. Major modes of
Arctic SIC variability are extracted from sea ice area fraction (concentration) data north of $40.5^{\circ} \mathrm{N}$. The SIC data present an integrated dataset from other operational products that are based on passive microwave satellite and conventional observation (Fiorino 2004; Donlon et al. 2012). The SIC analysis in the present study is robust as also confirmed by another sea ice concentration data from National Snow and Ice Data Center (NSIDC at nsidc.org).

To investigate atmospheric circulation associated with sea ice variation, 37 pressure-level $(1000-1 \mathrm{hPa})$ variables and potential vorticity on six potential temperature surfaces $(430,475,530,600,700$, and $850 \mathrm{~K})$ are analyzed.

In order to extract accurate physical mechanisms from the variables above, the cyclostationary empirical orthogonal function (CSEOF) technique is used (Kim 2017; Kim et al. 1996; Kim and North 1997; Seo and Kim 2003). Data are decomposed into mutually orthogonal CSEOF loading vectors (CSLV) and mutually uncorrelated principal component (PC) time series:

$T(r, t)=\sum_{n} \operatorname{CSLV}_{n}(r, t) P C_{n}(t)$,

$\operatorname{CSLV}_{n}(r, t)=\operatorname{CSLV}_{n}(r, t+d), \quad d=120$ days,

where $r$ and $t$ denote space and time, and $d$ is the nested period of CSEOF analysis. Each CSLV is periodic and consists of 120 daily spatial patterns that depict spatio-temporal evolution of the mode. The magnitude of CSLV varies according to corresponding PC (amplitude) time series.

Regression analysis in CSEOF space (Kim et al. 2015) is conducted to identify atmospheric anomaly that is physically consistent with each of the leading modes of SIC variability. Regression analysis in CSEOF space is carried out in the following manner:

Step 1: $P C_{n}^{(\text {sic) }}=\sum_{m=1}^{M} \alpha_{m}^{(n)} P C_{m}^{(\text {predictor })}(t)+\varepsilon^{(n)}(t)$,

Step 2: $\operatorname{CSLV}_{n}^{(\mathrm{reg})}=\sum_{m=1}^{M} \alpha_{m}^{(n)} \operatorname{CSLV}_{m}^{(\text {predictor) }}(r, t)$,

where $P C_{n}^{(\text {sic) }}$ is the $n$th PC time series of the target variable (sea ice area fraction in the present study), $C S L V_{m}^{\text {(predictor) }}(r, t)$ and $P C_{m}^{\text {(predictor) }}(t)$ are the $m$ th CSLV and PC time series of another variable (called the predictor variable), $\alpha_{m}^{(n)}$ and $\varepsilon^{(n)}(t)$ are regression coefficient and regression error time series, respectively. The regressed CSLV of the predictor variable, $C S L V_{n}^{(\mathrm{reg})}$, evolves in consistence with the $n$th mode of sea ice variability. After regression analysis in CSEOF space, the entire dataset can be written in the form: 
$\operatorname{Data}(r, t)=\sum_{n}\left\{\operatorname{sic}_{n}(r, t), \operatorname{gph}_{n}(r, t), \operatorname{airt}_{n}(r, t), \cdots\right\} P C_{n}^{(\mathrm{sic})}$,

where the terms in curly braces are (regressed) loading vectors derived from different variables. They share the PC time series of SIC variability and are regarded as physically consistent with each other. It should be noted that regressed variables are physically consistent with SIC variability only if regression error is zero. Otherwise, regression error may contaminate the loading vectors. All 120-day patterns of CSLV are examined but for the sake brevity time-mean or area-mean evolutions are used to highlight notable features. The results are based on anomalies after the seasonal cycle is removed.

\section{Results}

\subsection{Major modes of Arctic sea ice variability in winter}

Figure 1 shows monthly averaged patterns of the first two leading modes of daily SIC anomalies during November-February; this period is particularly chosen in order to isolate the winter anomaly patterns of sea ice without much contamination from the widespread pattern of sea ice reduction in fall (Kim et al. 2016). SIC anomalies develop within the seasonal excursion of SIC boundaries (magenta and navy contours in Fig. 1a-d, f-i). Similar SIC patterns can be obtained by conducting EOF analysis followed by composite analysis.

The first CSEOF mode represents Arctic SIC reduction throughout the winter and accounts for $29 \%$ of the total variance; SIC reduction is particularly prominent in the Barents and Kara Seas (BKS). The corresponding PC time series shows an accelerating trend of Arctic SIC decline together with naturally occurring interannual variability; the rate of SIC reduction appears to have increased significantly since 2004/2005 (Fig. 1e).

The second CSEOF mode exhibits a dipole pattern from December with anomalies of opposite signs between the east and west of the North Atlantic. Weak SIC anomalies are also seen in the Pacific sector. This mode explains 9\% of the total variance. It is known that this dipole pattern of SIC change is associated with North Atlantic Oscillation (NAO) (Deser et al. 2000; Strong and Magnusdottir 2010). The PC time series of the second mode shows interannual and decadal-scale fluctuations of SIC dipole anomalies (Fig. 1j) and is correlated at -0.4 with $\mathrm{a} \pm 60$-day smoothed NAO index (Fig. S1, archived at https://www.cpc.ncep.noaa. gov/products/precip/CWlink/pna/nao_index.html). From the mid-1990s to the early-2010s, positive SIC anomalies in the eastern North Atlantic (Barents and Greenland Seas) and negative anomalies in the western North Atlantic (Hudson Bay and Labrador Sea) have been frequently observed (Fig. 1j). In recent few years, the amplitude of the dipole pattern has been small.

\subsection{Characteristics of anomalous tropospheric circulation}

Arctic warming is conspicuous in the first mode (Fig. 2a-d). Atmospheric warming coexists with sea ice decline in the BKS and Chukchi Sea (Fig. 1a-d, 2a-d), which is significantly related to increased heat flux over the region of sea ice reduction (Kim et al. 2016, 2019; Screen and Simmonds 2010). Warm SST anomalies are also seen near the region of sea ice loss (figure not shown). The positive air temperature anomaly in the Pacific sector of the Arctic Ocean is seen for November-December, but the positive anomaly in the BKS persists throughout the winter (Fig. 2a-d). Weak cooling over Siberia and East Asia can be explained via cold advection due to the anticyclone centered in the BKS (Kim and Son 2016; Zhang et al. 2018). Warm Arctic and cold Eurasia is a characteristic pattern of Arctic amplification associated with Arctic SIC decline (Cohen et al. 2014; Mori et al. 2014; Overland et al. 2011). The positive height anomaly around the region of BKS warming, which becomes stronger in January, is a prominent feature of mid-tropospheric circulation in the first mode. In addition, negative height anomaly over Siberia and East Asia seems to be associated with Rossby wave response to SIC reduction in the BKS (Honda et al. 2009; Kim et al. 2014; Nakamura et al. 2015). On the other hand, causality between tropospheric circulation, such as anticyclone around the BKS (Ural blocking) or Eurasian cooling, and SIC reduction in the BKS is still questionable. Some studies suggest that tropospheric variation is caused by the SIC reduction in BKS (Kim et al. 2014; McKenna et al. 2018; Mori et al. 2014; Zhang et al. 2018), while others suggest that tropospheric variation represents internal climate variability (Blackport et al. 2019; Peings 2019 and references therein). It should be noted that the surface air temperature patterns associated with the first SIC mode differs significantly from those of global warming (see supplementary information, Figs. S7 and S8).

The second mode shows positive mid-tropospheric geopotential height anomalies around the Iceland and southern Greenland and negative anomalies along $\sim 40^{\circ} \mathrm{N}$ of the North Atlantic (Fig. 2e-h). This structure is salient in December-January and resembles the negative phase of NAO. The accompanying temperature anomalies in high latitudes display opposite variations between the eastern and western hemispheres. In November, warm anomalies develop around the Hudson-Baffin Bay and the Chukchi Sea where negative SIC anomalies exist (Fig. 2e). Anomalous anticyclone established over the Greenland from late 

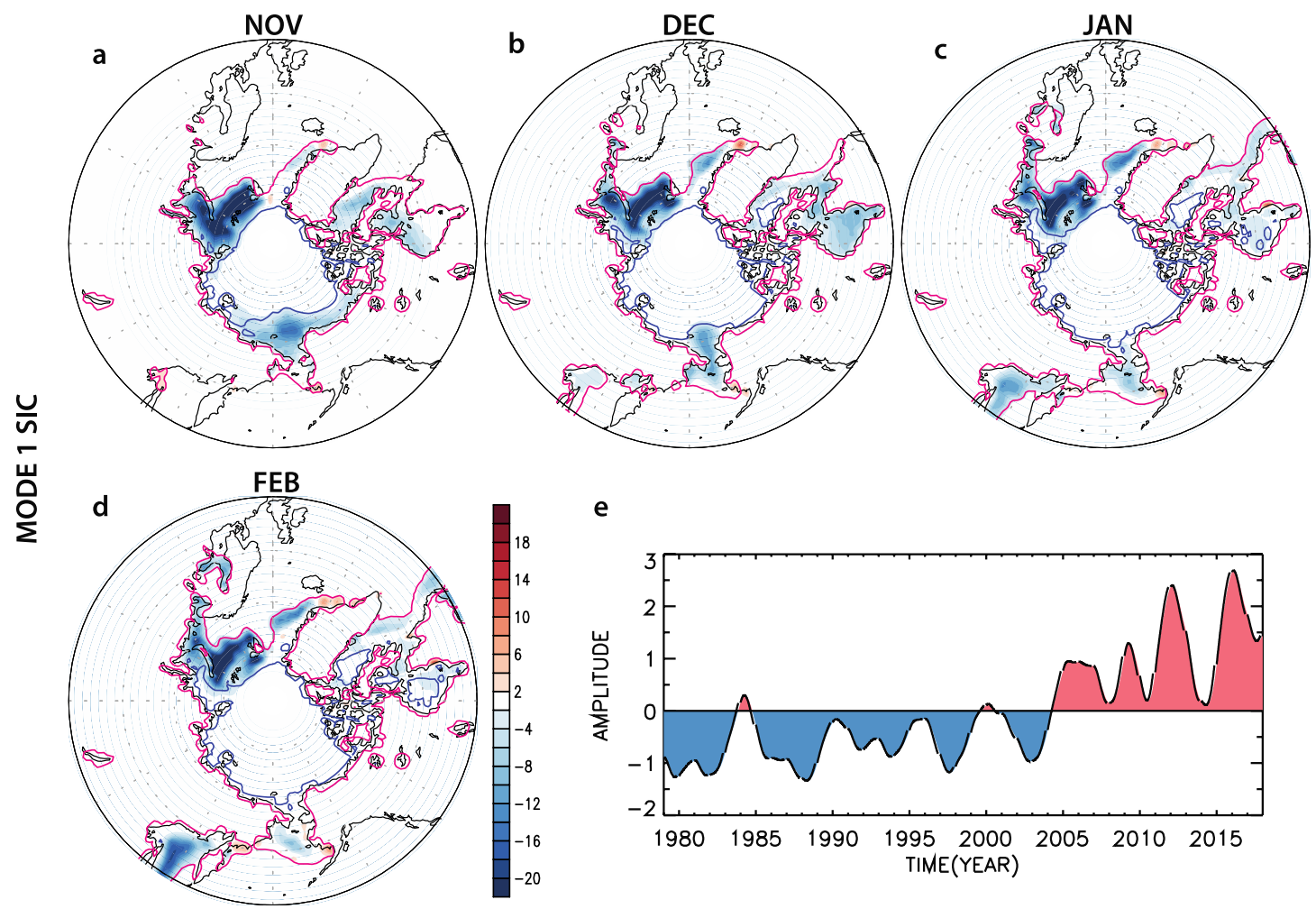

e
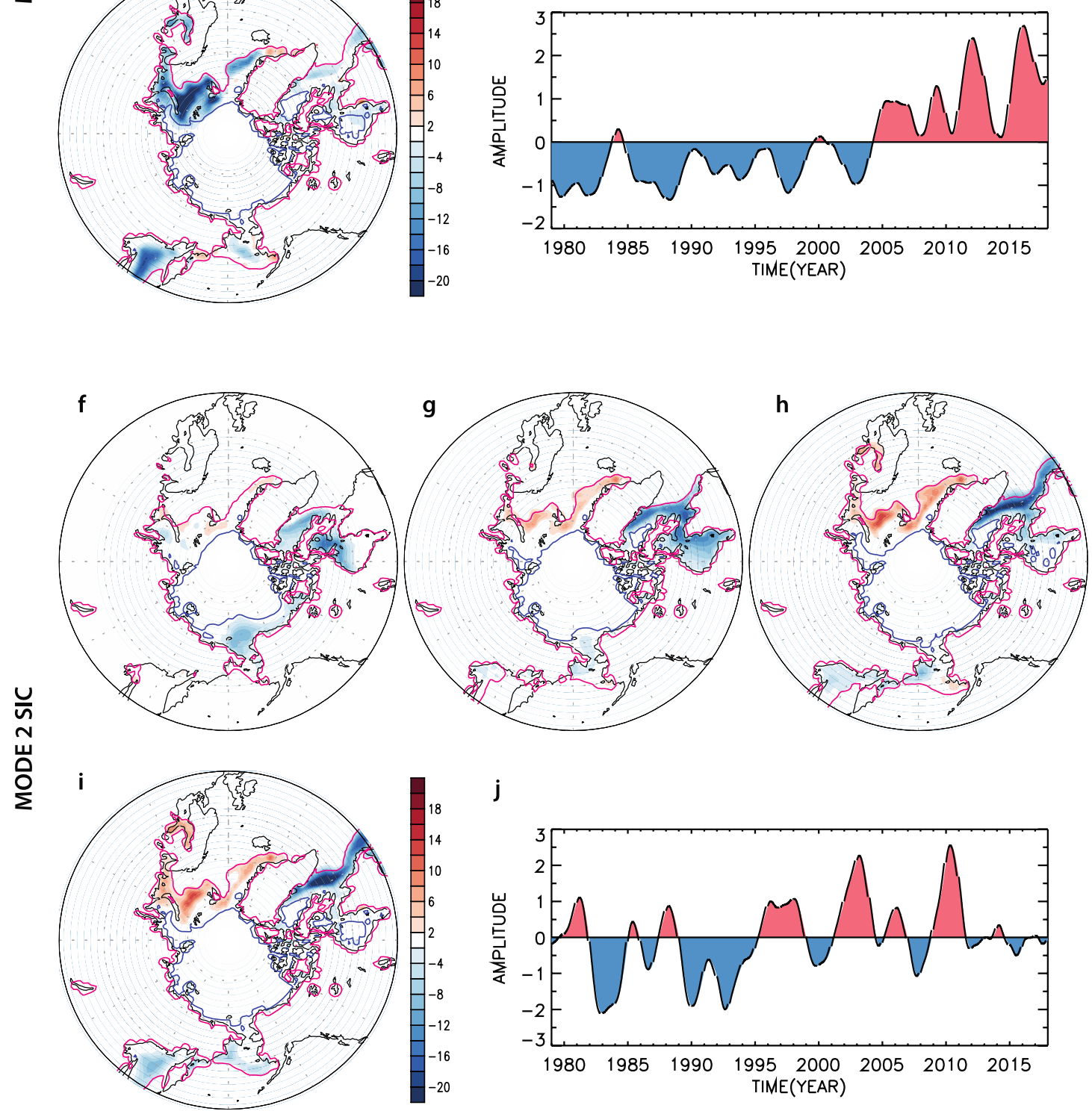

j

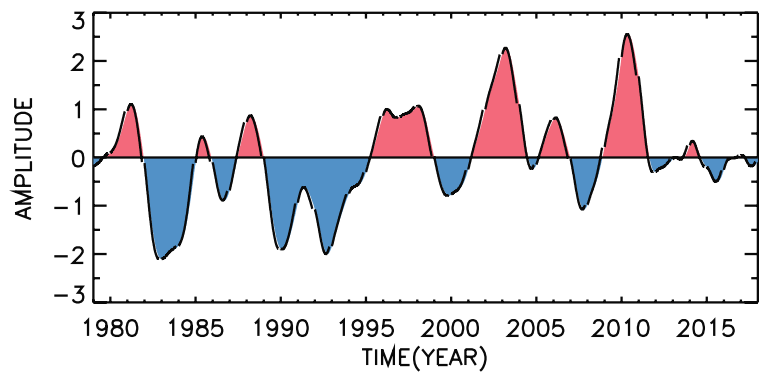

Fig. 1 Monthly-averaged patterns of anomalous sea ice cover (\%) for $\mathbf{a}-\mathbf{d}$ the first and $\mathbf{f}-\mathbf{i}$ the second CSEOF mode derived from the November-February sea ice area fraction (concentration) data over the domain $\left(40.5^{\circ} \mathrm{N}-87^{\circ} \mathrm{N}\right)$, and $\mathbf{e}, \mathbf{j}$ the corresponding PC time series. The magenta and navy contours represent $5 \%$ and $95 \%$ sea ice isopleths in the climatological seasonal cycle 


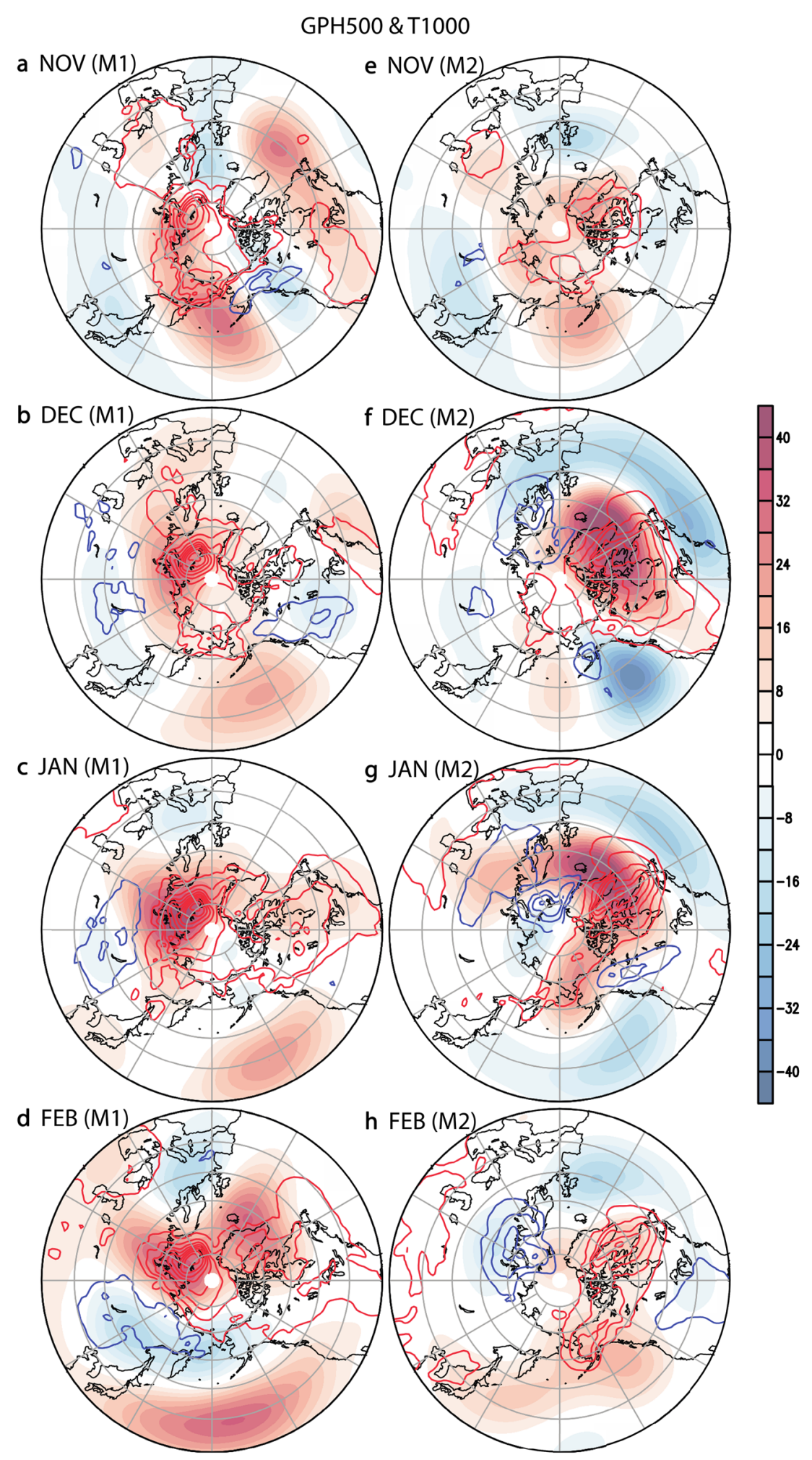

Fig. 2 Monthly-averaged patterns of 500-hPa geopotential height anomalies (shading) and 1000-hPa air temperature anomalies [red (+) and blue (-) contours at $0.5 \mathrm{~K}$ interval] for $\mathbf{a}-\mathbf{d}$ the first CSEOF mode and $\mathbf{e}-\mathbf{h}$ the second mode of sea ice variability 

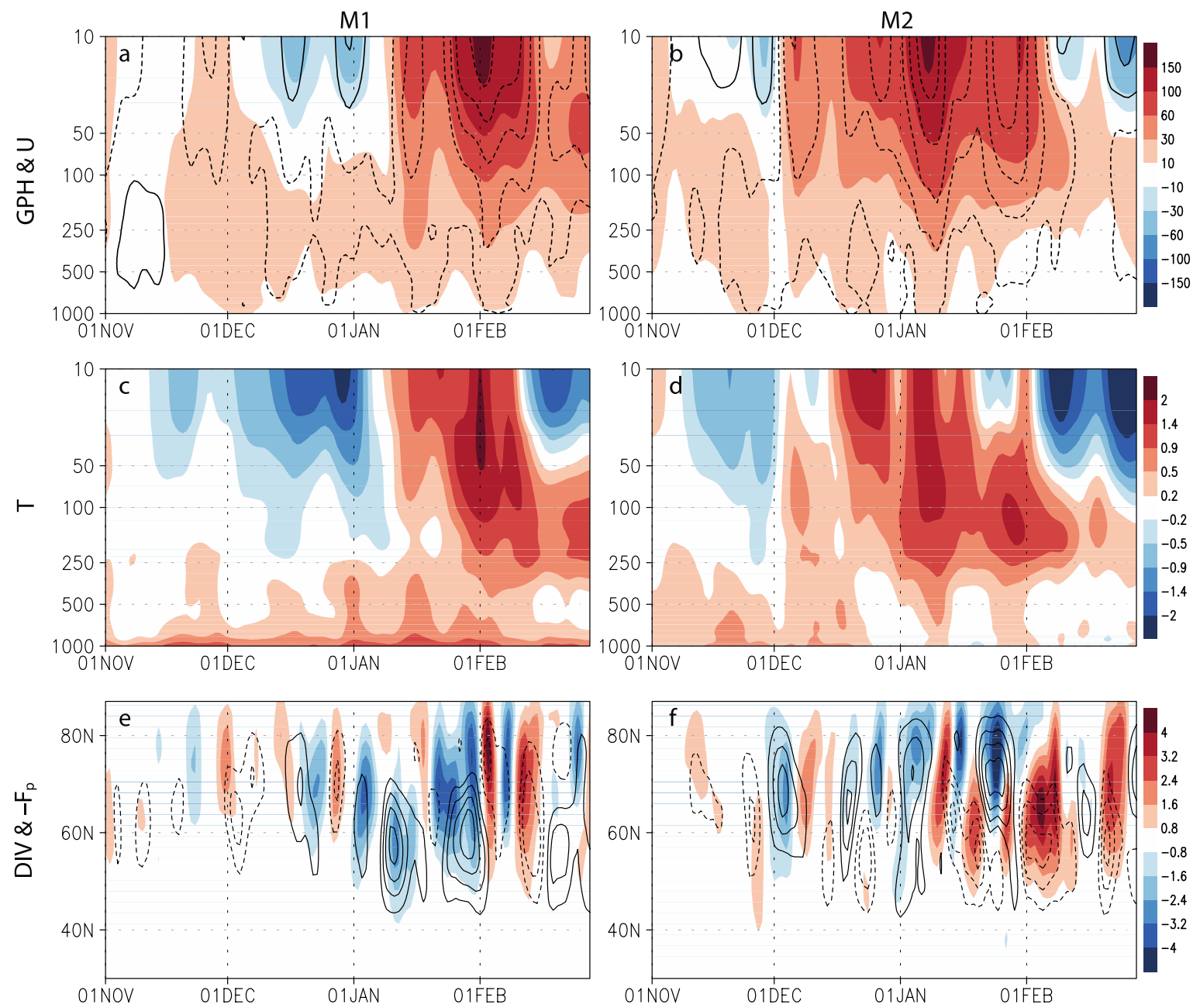

Fig. 3 Time-altitude pattern of $\mathbf{a}, \mathbf{b}$ polar cap $\left(0^{\circ} \mathrm{E}-360^{\circ} \mathrm{E}, 64.5^{\circ}\right.$ $\mathrm{N}-87^{\circ} \mathrm{N}$ ) mean geopotential height (shading) and zonal-mean zonal wind at $60^{\circ} \mathrm{N}$ (contoured at $1.0 \mathrm{~m} \mathrm{~s}^{-1}$ interval from $\pm 0.5 \mathrm{~m} \mathrm{~s}^{-1}$ ) and $\mathbf{c}, \mathbf{d}$ polar cap mean air temperature anomalies, and $\mathbf{e}, \mathbf{f}$ time-latitude

November advects cold (warm) air toward the Barents Sea and northern Europe (the Labrador Sea and the Baffin Bay). Accordingly, cold anomalies will increase SIC over the Barents and the Greenland Seas and warm anomalies will reinforce SIC decline over the Hudson Bay and the Labrador Sea (Fig. 2f).

The circulation change is physically consistent with the dipole pattern of SIC anomaly, which is seen from late November (Fig. 1f-i). Warm SST anomaly in the Labrador Sea and cold SST anomaly in the Barents-Greenland Seas coincide with the opposite signs of SIC anomalies (figure not shown). Existing SST anomalies seem to be intensified with the development of the dipole structure and reach its maximum in January. Therefore, the second mode can be interpreted as a dipole SIC variation in the Atlantic sector driven by NAO-like atmospheric circulation (Deser et al.

evolution of the divergence of EP flux anomaly at $10 \mathrm{hPa}$ (shading) and the vertical component of EP flux at $100 \mathrm{hPa}$ (contoured at $1 \times 10^{5} \mathrm{~Pa} \mathrm{~m}^{2} \mathrm{~s}^{-2}$ interval, positive upward) for the first (left column) and second (right column) CSEOF modes

2000; Deser and Teng 2008). Statistical significance for Fig. 2 is provided in the supplementary information (Fig. S9).

\subsection{Variation of stratospheric polar vortex strength}

Figure 3 displays vertical evolutions of polar-cap $\left(0^{\circ} \mathrm{E}-360^{\circ}\right.$ E, $64.5^{\circ} \mathrm{N}-87^{\circ} \mathrm{N}$ ) mean geopotential height $(\mathrm{PCH})$, temperature (PCT), and zonal-mean zonal wind anomalies. They, as a proxy for the Northern annular mode (Baldwin and Dunkerton 2001; Baldwin and Thompson 2009), describe variations in strength of stratospheric polar vortex. The positive anomalies in the stratospheric PCH indicate a weakening of stratospheric polar vortex. The two leading modes of SIC variability show different evolution of $\mathrm{PCH}$ (Fig. 3a, b). In the first mode, positive $\mathrm{PCH}$ anomaly develops strongly in the stratosphere from mid-January following the negative anomaly in December, and eventually extends to the 
troposphere. The positive $\mathrm{PCH}$ coincides with a deceleration of the polar night jet and an increase in Arctic stratospheric temperature (Fig. 3a, c). This pattern indicates that a strong winter reduction of Arctic SIC is linked with stratospheric vortex weakening during mid-January-late February. In late February, there is still positive $\mathrm{PCH}$ anomaly in the stratosphere but it is weak and develops at relatively low altitudes.

The second mode, which corresponds to positive SIC anomaly in the Barents and Greenland Seas and negative anomaly in the Labrador Sea and Hudson Bay (Fig. 1f-i), shows positive $\mathrm{PCH}$ and PCT anomalies in the stratosphere from December to early February together with anomalous easterly wind (Fig. 3b, d). The positive anomalies persist through February in the lower stratosphere. Anomalous stratospheric vortex strengthening comes after the vortex weakening; this vortex strengthening is significant at the 95\% level. Unlike the first mode, the negative PCT anomalies occurring after the vortex weakening are stronger than that before the vortex weakening in November. The vortex strengthening, however, is limited to the stratosphere.

Figure $3 \mathrm{e}, \mathrm{f}$ show the evolution of vertical Eliassen-Palm (EP) flux (see supplementary information for details) at $100 \mathrm{hPa}$ and divergence of EP flux at $10 \mathrm{hPa}$. In the first mode, upward EP flux anomalies are dominant near $60^{\circ} \mathrm{N}$ from early January, just before upper-stratospheric anomalous easterly develops, to the end of January, just before upper-stratospheric anomalous easterly reaches its maximum (Fig. 3e). The anomalous upward EP flux converges at higher altitudes, resulting in the deceleration of stratospheric westerly wind and the weakening of stratospheric polar vortex (Fig. 3a, e). In the second mode, upward EP flux anomaly and its convergence during December-January are dynamically consistent with occurrence of upper-stratospheric anomalous easterlies and explain each extremum of easterly wind reasonably (Fig. 3f). During mid-late January, anomalous convergence is limited to high latitudes and anomalous divergence begins to develop in lower latitudes.

Upward EP flux anomalies can be partly explained in terms of constructive interference between climatological planetary-scale waves and SIC-related wave anomalies (Garfinkel et al. 2010; Nishii et al. 2009; Smith et al. 2010; Smith and Kushner 2012). Anomalous high around the BKS and anomalous low around Siberia in the first mode, and anomalous high around the Greenland in the second mode are advantageous for increasing upward propagation of EP flux through amplification of climatological waves (Figs. S3 and S4). However, increase in upward propagation of EP flux is attributable to non-negligible nonlinear part associated with interactions among anomalous waves, in addition to the linear interference (Fig. S2).

The stratospheric vortex variation depends on how well the tropospheric circulation amplifies climatological waves and thus increases the upward propagation of the waves.
Thus, although SIC reduction and the resulting warming over the BKS are already strong from November in the first mode, substantial wave propagation occurs only after mid-December. As a result, strong vortex weakening in the first mode appears later than in the second mode.

\subsection{Geometric characteristics of stratospheric anomalies during polar vortex weakening}

Variation in the strength of stratospheric vortex is estimated in terms of zonal-mean and Arctic-mean anomalies (Fig. 3). It should be noted, however, that stratospheric anomalies are neither zonally symmetric nor their centers are at the pole. In this regard, area mean or zonal mean field is not a sufficiently accurate depiction of stratospheric vortex variations. To characterize the detailed evolution of stratospheric anomalies, therefore, geometric structures of anomalies should be examined further.

Figures 4 and 5 show the five-stage horizontal evolution of stratospheric anomalies corresponding to the development of the polar vortex weakening. Based on the date of the maximum intensity of $10-\mathrm{hPa} \mathrm{PCH}$ anomaly, the vortex weakening event is divided into five stages between Jan 5 and Feb 28 (11-day interval) for the first mode, and Nov 26 and Feb 18 (17-day interval) for the second mode. Statistical significance for the regressed loading vectors in Figs. 4 and 5 can be found in the supplementary information (Figs. S10 and S11). Since the duration of the anomalous positive stratospheric PCH in the first mode is shorter than in the second mode (Fig. 3), we used 11-day averaged patterns for the first mode and 17-day averaged pattern for the second mode.

For the first mode, positive height anomaly develops in the upper stratosphere from the subpolar region and covers the entire Arctic $\left(>65^{\circ} \mathrm{N}\right)$ by stage 3 when the anomalous positive $\mathrm{PCH}$ reaches its maximum (Fig. $4 \mathrm{a}-\mathrm{c}$ ). The mature phase of the positive height anomaly is circular and its center of action is slightly shifted toward North America (Fig. 4c). The positive anomaly is surrounded by negative anomalies and the anomalous easterly along the boundary of the positive height anomaly extends to lower latitudes $\left(\sim 30^{\circ} \mathrm{N}\right)$ in the western hemisphere (Fig. 4h). During stages 4 and 5, the negative height anomalies in mid-latitudes expand toward the pole and the positive anomaly over the polar region is attenuated in the form of an ellipse (Fig. 4d, e).

The positive temperature anomalies and the negative potential vorticity (PV) anomalies over the Arctic (Fig. 4f-o) are physically consistent with the positive height anomalies. The PV anomalies reflect the lower stratospheric variations and strong negative anomalies in the Arctic persist in later stages (Fig. $4 \mathrm{~m}-\mathrm{O}$ ). In addition to the decreasing intensity of the stratospheric polar vortex, the edge of vortex based on a constant value of the climatological potential vorticity shows a slight shift of 

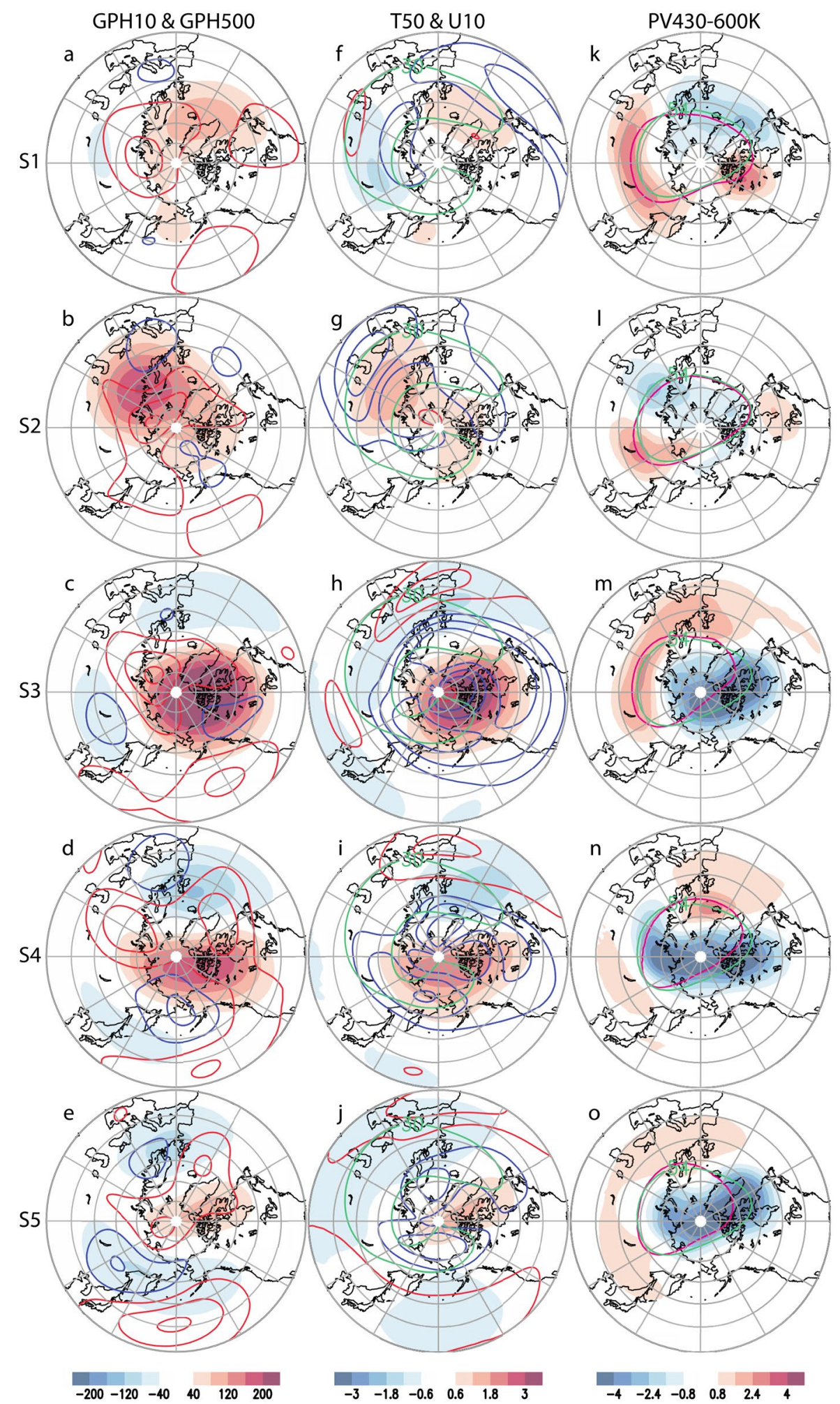

Fig. 4 Five-stage evolution of a-e 10-hPa (shading) and 500-hPa [red $(+)$ and blue $(-)$ contours at $\pm 10,30$, and $50 \mathrm{~m}$ ] geopotential height anomalies, $\mathbf{f}-\mathbf{j}$ 50-hPa temperature anomalies (shading) and $10-\mathrm{hPa}$ zonal wind (red and blue contours at $\pm 2,4$, and $6 \mathrm{~m} \mathrm{~s}^{-1}$ ) with climatological $30 \mathrm{~m} \mathrm{~s}^{-1}$ zonal wind (aqua contour), and k-o the vertically averaged (430-600 K) potential vorticity anomalies [shading, $0.8 \mathrm{PVU}\left(10^{-6} \mathrm{~K} \mathrm{~m}^{2} \mathrm{~kg}^{-1} \mathrm{~s}^{-1}\right)$ interval] with climatological potential vorticity (aqua contour at $54 \mathrm{PVU}$ ) and the perturbed potential vorticity (magenta contour at $54 \mathrm{PVU}$ ) for the first CSEOF mode. The perturbed potential vorticity is obtained by adding the climatology with the $2 \sigma$ values of the anomalous potential vorticity. Each pattern represents an 11-day average based on the development of positive PCH anomaly at $10 \mathrm{hPa}$ with its maximum in stage 3 

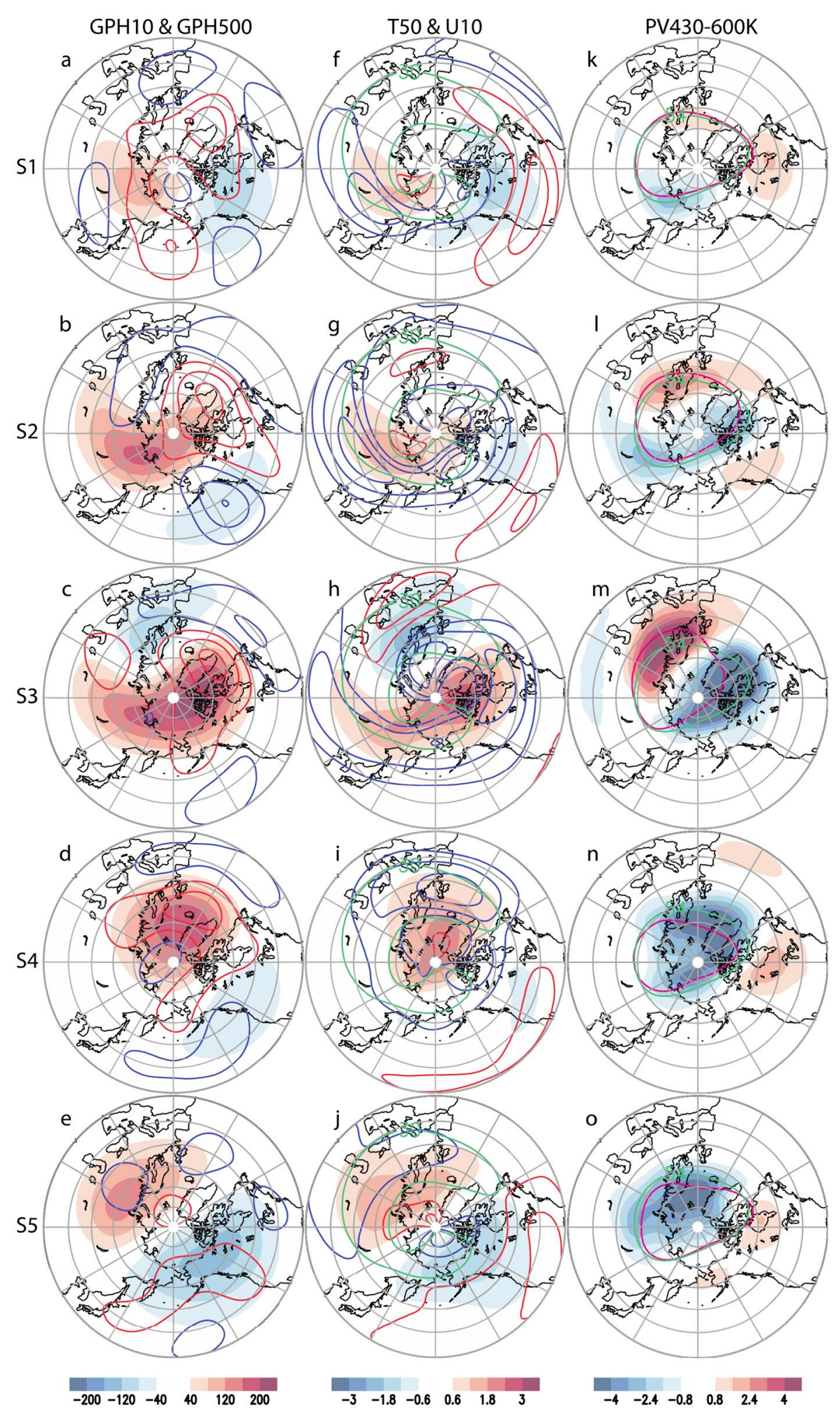

Fig. 5 Five-stage evolution of a-e 10-hPa (shading) and 500-hPa [red $(+)$ and blue $(-)$ contours at $\pm 10,30$, and $50 \mathrm{~m}$ ] geopotential height anomalies, $\mathbf{f}-\mathbf{j}$ 50-hPa temperature anomalies (shading) and $10-\mathrm{hPa}$ zonal wind (red and blue contours at $\pm 2,4$, and $6 \mathrm{~m} \mathrm{~s}^{-1}$ ) with climatological $30 \mathrm{~m} \mathrm{~s}^{-1}$ zonal wind (aqua contour), and $\mathbf{k}-\mathbf{o}$ the vertically averaged $(430-600 \mathrm{~K})$ potential vorticity anomalies [shading, 0.8 PVU $\left(10^{-6} \mathrm{~K} \mathrm{~m}^{2} \mathrm{~kg}^{-1} \mathrm{~s}^{-1}\right)$ interval] with climatological potential vor- ticity (aqua contour at $54 \mathrm{PVU}$ ) and the perturbed potential vorticity (magenta contour at 54 PVU) for the second CSEOF mode. The perturbed potential vorticity is obtained by adding the climatology with the $2 \sigma$ values of the anomalous potential vorticity. Each pattern represents a 17-day average based on the development of positive PCH anomaly at $10 \mathrm{hPa}$ with its maximum in stage 3 
Fig. 6 Five-stage evolutions of $10-\mathrm{hPa}$ climatological zonal wind maximum (filled circle) and perturbed zonal wind maximum (cross) at each longitude grid in the a-e first and $\mathbf{f}-\mathbf{j}$ second CSEOF modes. Symbols are located at every five longitude grids. The color of the cross symbol indicates the degree to which the perturbed field deviates from the climatological field. Each pattern represents a-e an 11-day average for the first mode and $\mathbf{f}-\mathbf{j}$ a 17-day average for the second mode, as shown in Figs. 4 and 5
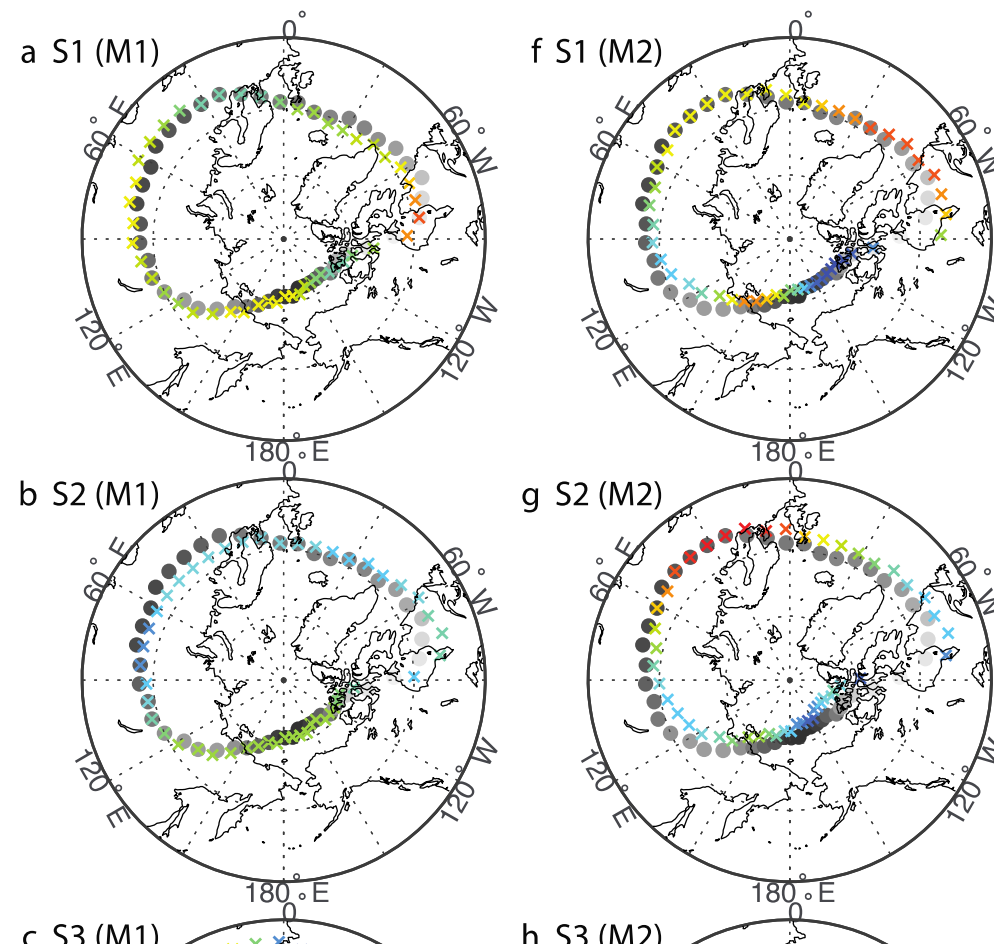

g S2 (M2)

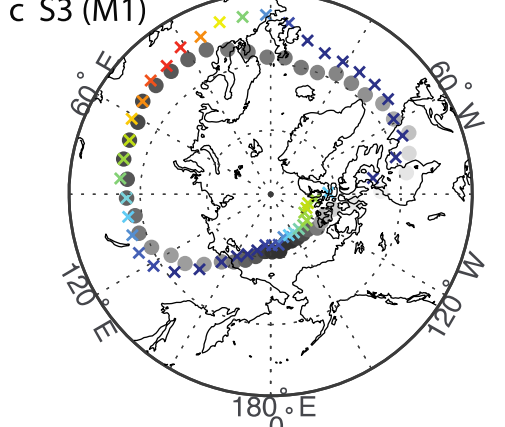

h S3 (M2)

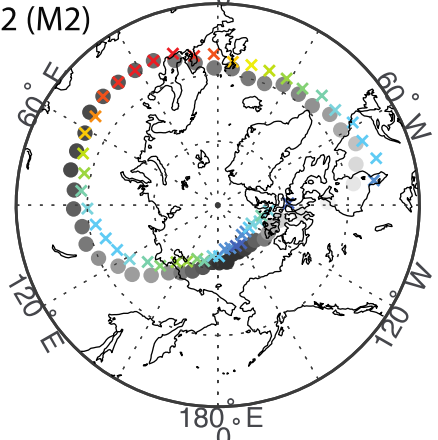

45

40

35

30

25

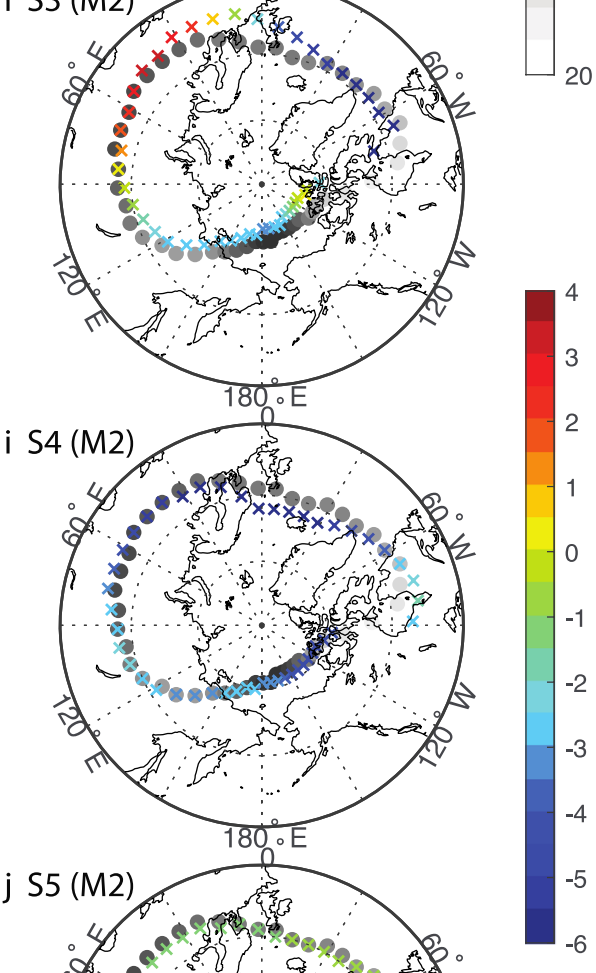

e $55(\mathrm{M} 1)$

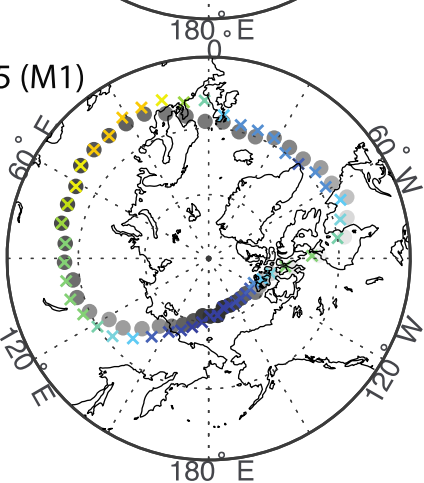


vortex toward Eurasia in stage 3 (magenta contour line in Fig. $4 \mathrm{~m}$ ), a result similar to Zhang et al. (2016). This is because the strong negative PV anomaly over the northern Canada acts to move the western edge of the vortex toward the Pole and the weak positive anomaly in the subpolar Eurasia acts to move the eastern edge toward the south (Fig. 4m, Fig. S5m, S5r).

The position of maximum zonal wind speed, another definition of the boundary of stratospheric polar vortex (Waugh et al. 2017), also shows a similar shift in the upper stratosphere (10 hPa) (Fig. 6c). While in the lower stratosphere southward migration of the vortex boundary is seen uniformly in the Eurasia region, in the upper stratosphere it is more pronounced in Siberia and the North Atlantic (Figs. 4m, 6c and Fig. S5m, S5r). In addition, polar night jet slows down except in $10^{\circ} \mathrm{E}-60^{\circ} \mathrm{E}$ (Fig. 6c). This uneven change indicates that the pattern of zonal-wind anomalies during the vortex weakening does not necessarily coincide with that of climatological wind (Fig. $4 \mathrm{~m}$ ).

For the second mode, positive geopotential anomaly is developed from the northeastern Russia in stage 1 and occupies the polar region in stage 3 (Fig. $5 \mathrm{a}-\mathrm{c}$ ). In stage 3 , the positive anomaly is elongated in the $90^{\circ} \mathrm{E}-90^{\circ} \mathrm{W}$ direction and has a bean-like shape that envelops the negative anomaly over Europe. The maximum height anomaly is shifted toward North America as in the first mode. Unlike the first mode with a high anomaly, however, the second mode shows a low anomaly in Siberia (Figs. 4c, 5c). The anomalous easterly has an elongated spiral pattern along the high anomaly and extends to $30^{\circ} \mathrm{N}$ in the eastern hemisphere (Fig. 5h). The anomalous easterly contributes to slowing down polar night jet except in western Eurasia in which the anomalous westerly rather enhances local polar night jet (Fig. 6h). In stages 4 and 5, this positive height anomaly retreats toward Europe, and the negative anomaly over North America spreads toward the North Pole and becomes stronger (Fig. $5 \mathrm{~d}$, e).

Temperature and potential vorticity anomalies evolve in a similar fashion with the geopotential height anomalies (Fig. 5f-o). In stage 3, the positive PV anomaly over Europe and the negative PV anomaly over the northern Canada push the vortex to shift toward Europe (Fig. 5m, Fig. S6m, S6r). Polar night jet in the upper stratosphere $(10 \mathrm{hPa})$ more clearly shows the vortex movement toward Europe (Fig. 6h, Fig. S6r). In phase 5, however, the negative PV anomaly moves toward Europe and weak positive anomaly appears over the northern Canada (Fig. 5o).

The stratospheric polar vortices of the two modes not only show distinct evolutions in terms of timing and duration as can be seen in the development of polar cap averaged or zonally averaged anomalies (Fig. 3), but also exhibit different spatio-temporal structures of evolution (Figs. 4, 5, 6). The zonally asymmetric distribution of the anomalies in the mature phase contributes to a stratospheric vortex migration toward Eurasia in the first mode and toward Europe in the second mode (Figs. 4m, 5m, 6c, h). Three-dimensional evolution pictures also show these asymmetric structures of the two modes (Figs. S5 and S6 and Movies S1-S4). The circulation patterns for the two modes also differ in the troposphere (Figs. 5a-e, 6a-e). Stratospheric vortex weakening is accompanied by strong anticyclone near the BKS in the first mode, and strong anticyclone in the southern Greenland in the second mode. This implies cold advection over East Asia and warm advection over the BKS for the first mode, and cold advection over the BKS and warm advection over northeastern North America.

\section{Summary and discussion}

We have examined the leading modes of Arctic SIC variability for 39 winters (NDJF, 1979/80-2017/18) and delineated corresponding changes in stratospheric polar vortex. The first CSEOF mode represents an accelerating trend of winter sea ice reduction in the Arctic, particularly in the BKS. This mode is associated with Arctic amplification. The second CSEOF mode exhibits a dipole structure of SIC variation with an out-of-phase relationship between the eastern and western North Atlantic. This dipole pattern is formed by NAO-like circulation that dominates in December-January and exhibits decadal-scale phase shifts.

The SIC variations of the two modes are accompanied by distinct evolutions of stratospheric polar vortex both in time and space. A rapid sea ice reduction in the Arctic around the BKS in the first mode is related to a stratospheric polar vortex weakening in mid-January-late February. The dipole pattern corresponding to negative NAO-like circulation, the anomalous increase of SIC in the Barents and Greenland Seas and the anomalous decrease in the Labrador Sea and Hudson Bay, in the second mode is accompanied by a stratospheric vortex weakening in December-early February. It is not clear if there is any direct relationship between sea ice change and stratospheric vortex weakening; both stratospheric variation as well as sea ice change can be caused by tropospheric internal variability (NAO). The evolution of physical variables is described on the basis of timing. It should be noted that the sequence of evolution among different variables does not necessarily imply causality.

The stratospheric anomalies are zonally asymmetric. Geometric patterns can provide more detailed evolution properties of stratospheric anomalies. In the upper stratosphere, the fully-developed positive geopotential anomaly is of circular shape shifted toward North America in the first mode. In the second mode, it is elongated in the direction of Eurasia and North America. Accordingly, negative anomaly is seen over Siberia in the first mode and positive 
anomaly in the second mode. Difference in the spatial pattern of anomalies may imply distinct local impacts of polar vortex weakening.

It should be noted that stratospheric vortex weakening over the Barents Sea is related to the SIC reduction in the first mode and the SIC augmentation in the second mode. Several studies suggested that geographical location of SIC loss is an important factor in determining stratospheric response (Mckenna et al. 2018; Screen 2017a; Sun et al. 2015). Our result, on the other hand, indicates that stratospheric vortex variation depends on the overall pattern of SIC loss in the entire Arctic. Not only the timing of stratospheric vortex weakening, but also movement or deformation of vortex depend critically on the modal pattern of SIC reduction. In order to better understand SIC-related stratospheric vortex variation, therefore, it seems necessary to first identify the mode of SIC variability.

It is expected that stratospheric vortex weakening will occur frequently during mid-January to late February as SIC reduction accelerates. In addition, it can be predicted that in the mature stage the upper stratospheric vortex will move toward Eurasia and will change to a form elongated in the direction of Siberia and the North Atlantic. On the other hand, the amplitude of the Atlantic dipole SIC variations, which fluctuated significantly until the 2000s, has been small in recent years. Accordingly, the weakening (strengthening) of stratospheric vortex in December-January, which tends to migrate toward the Europe (Pacific) in the mature stage, has decreased.

The stratospheric vortex fluctuations associated with the two leading SIC modes account for approximately $6 \%(14 \%)$ of the total variance of $10 \mathrm{hPa}(100 \mathrm{hPa})$ $\mathrm{PCH}$ index. This implies that the internal variability of stratospheric vortex away from the major SIC variability is greater than the SIC-related vortex variation. Nevertheless, this study is meaningful in that it distinguishes the distinct evolution aspects of stratospheric variations related to the major modes of SIC variability. Comparison of these modes allowed us to identify SIC-stratospheric vortex relationship under different physical conditions arising from forced climate change and natural variability. It also improves understanding of vortex variations associated with SIC fluctuations by additionally investigating the zonally asymmetric features of the spatial structures.

Acknowledgements This research was supported by the National Science Foundation of Korea under the Grant number NRF-2017R1A2B4003930.

Open Access This article is licensed under a Creative Commons Attribution 4.0 International License, which permits use, sharing, adaptation, distribution and reproduction in any medium or format, as long as you give appropriate credit to the original author(s) and the source, provide a link to the Creative Commons licence, and indicate if changes were made. The images or other third party material in this article are included in the article's Creative Commons licence, unless indicated otherwise in a credit line to the material. If material is not included in the article's Creative Commons licence and your intended use is not permitted by statutory regulation or exceeds the permitted use, you will need to obtain permission directly from the copyright holder. To view a copy of this licence, visit http://creativecommons.org/licenses/by/4.0/.

\section{References}

Baldwin MP, Dunkerton TJ (2001) Stratospheric harbingers of anomalous weather regimes. Science 294:581-584

Baldwin MP, Thompson DWJ (2009) A critical comparison of stratosphere-troposphere coupling indices. Q J R Meteorol Soc 135:1661-1672

Blackport R, Screen JA, van der Wiel K, Richard B (2019) Minimal influence of reduced Arctic sea ice on coincident cold winters in mid-latitudes. Nat Clim Change 9:697-704. https://doi. org/10.1038/s41558-019-0551-4

Cohen J, Screen JA, Furtado JC et al (2014) Recent Arctic amplification and extreme mid-latitude weather. Nat Geosci 7:627-637

Cohen J, Pfeiffer K, Francis JA (2018) Warm Arctic episodes linked with increase frequency of extreme winter weather in the United States. Nat Commun 9:869. https://doi.org/10.1038/s4146 7-018-02992-9

Dee DP, Uppala SM, Simmons AJ et al (2011) The ERA-interim reanalysis: configuration and performance of the data assimilation system. Q J R Meteorol Soc 137:553-597

Deser C, Teng H (2008) Evolution of Arctic sea ice concentration trends and the role of atmospheric circulation forcing, 1979-2007. Geophys Res Lett 35:L020504. https://doi. org/10.1029/2007GL032023

Deser C, Walsh JE, Timlin MS (2000) Arctic sea ice variability in the context of recent atmospheric circulation trends. J Clim 13:617-633

Donlon CJ, Martin M, Stark J, Roberts-Jones J, Fiedler E, Wimmer W (2012) The operational sea surface temperature and sea ice analysis (OSTIA) system. Remote Sens Environ 116:140-158. https://doi.org/10.1016/j.rse.2010.10.017

Fiorino M (2004) A multi-decadal daily sea surface temperature and sea ice concentration data set for the ERA-40 reanalysis. ERA-40 Project Report Series 12:1-16

Garfinkel CI, Hartmann DL, Sassi F (2010) Tropospheric precursors of anomalous northern hemisphere stratospheric polar vortices. J Clim 23:3282-3299

Hassanzadeh P, Kuang Z (2015) Blocking variability: Arctic amplification versus Arctic oscillation. Geophys Res Lett 42:8586-8595. https://doi.org/10.1002/2015GL065923

Honda M, Inoue J, Yamane S (2009) Influence of low Arctic sea-ice minima on anomalously cold Eurasian winters. Geophys Res Lett 36:L08707. https://doi.org/10.1029/2008GL037079

Hoshi K, Ukita J, Honda M, Iwamoto K, Nakamura T, Yamazaki K, Dethloff K, Jaiser R, Handorf D (2017) Poleward eddy heat flux anomalies associated with recent Arctic sea ice loss. Geophys Res Lett 44:446-454. https://doi.org/10.1002/2016GL071893

Hoshi K, Ukita J, Honda M, Nakamura T, Yamazaki K, Miyoshi Y, Jaiser R (2019) Weak stratospheric polar vortex events modulated by the Arctic sea-ice loss. J Geophys Res Atmos 124:858-869. https://doi.org/10.1029/2018JD029222

$\mathrm{Hu}$ A, Rooth C, Bleck R, Deser C (2002) NAO influence on sea ice extent in the Eurasian coastal region. Geophys Res Lett 29:2053. https://doi.org/10.1029/2001GL014293 
Jaiser R, Nakamura T, Handorf D, Dethloff K, Ukita J, Yamazaki K (2016) Atmospheric winter response to Arctic sea ice changes in reanalysis data and model simulations. J Geophys Res Atmos 121:7564-7577. https://doi.org/10.1002/2015JD024679

Kim KY (2017) Cyclostationary EOF analysis: theory and applications. SNU Press, Kolkata

Kim KY, North GR (1997) EOFs of harmonizable cyclostationary processes. J Atmos Sci 54:2416-2427

Kim KY, Son SW (2016) Physical characteristics of Eurasian winter temperature variability. Environ Res Lett 11:044009. https://doi. org/10.1088/1748-9326/11/4/044009

Kim KY, North GR, Huang J (1996) EOFs of one-dimensional cyclostationary time series: computations, examples, and stochastic modeling. J Atmos Sci 53:1007-1017

Kim BM, Son SW, Min SK, Jeong JH, Kim SJ, Zhang X, Shim T, Yoon JH (2014) Weakening of the stratospheric polar vortex by Arctic sea-ice loss. Nat Commun 5:4646. https://doi.org/10.1038/ ncomms 5646

Kim KY, Hamlington BD, Na H (2015) Theoretical foundation of cyclostationary EOF analysis for geophysical and climatic variables: concepts and examples. Earth Sci Rev 150:201-218

Kim KY, Hamglington BD, Na H, Kim J (2016) Mechanism of seasonal Arctic sea ice evolution and Arctic amplification. Cryosphere 10:2191-2202. https://doi.org/10.5194/tc-10-2191-2016

Kim KY, Kim J, Kim J, Yeo S, Na H, Hamlington BD, Leben RR (2019) Vertical feedback mechanism of winter Arctic amplification and sea ice loss. Sci Rep 9:1184. https://doi.org/10.1038/ s41598-018-38109-x

Kretschmer M, Coumou D, Donges JF, Runge J (2016) Using causal effect networks to analyze different Arctic drivers of midlatitude winter circulation. J Clim 29:4069-4081

Lawrence ZD, Manney GL (2018) Characterizing stratospheric polar vortex variability with computer vision techniques. J Geophys Res Atmos 123:1510-1535. https://doi.org/10.1002/2017JD027556

Magnusdottir G, Deser C, Saravanan R (2004) The effects of North Atlantic SST and sea ice anoamlies on the winter circulation in CCM3. Part I: Main features and storm track characteristics of the response. J Clim 17:857-876

McKenna CM, Bracegirdle TJ, Shuckburgh EF, Haynes PH, Joshi MM (2018) Arctic sea ice loss in different regions leads to contrasting northern hemisphere impacts. Geophys Res Lett 45:945-954. https://doi.org/10.1002/2017GL076433

Mitchell DM, Gray LJ, Anstey J, Baldwin MP, Charlton-Perez AJ (2013) The influence of stratospheric vortex displacements and splits on surface climate. J Clim 26:2668-2682

Mori M, Watanabe M, Shiogama H, Inoue J, Kimoto M (2014) Robust Arctic sea-ice influence on the frequent Eurasian cold winters in past decades. Nat Geosci 7:869-873. https://doi.org/10.1038/ ngeo2277

Nakamura T, Yamazaki K, Iwamoto K, Honda M, Miyoshi Y, Ogawa Y, Ukita J (2015) A negative phase shift of the winter AO/NAO due to the recent Arctic sea-ice reduction in late autumn. J Geophys Res Atmos 120:3209-3227. https://doi.org/10.1002/2014J D022848

Nakamura T, Yamazaki K, Iwamoto K, Honda M, Miyoshi Y, Ogawa Y, Tomikawa Y, Ukita J (2016) The stratospheric pathway for Arctic impacts on midlatitude climate. Geophys Res Lett 43:3494-3501. https://doi.org/10.1002/2016GL068330

Nishii K, Nakamura H, Miyasaka T (2009) Modulations in the planetary wave field induced by upward-propagating Rossby wave packets prior to stratospheric sudden warming events: a casestudy. Q J R Meteorol Soc 135:39-52

Overland JE, Wood KR, Wang M (2011) Warm Arctic-cold continents: climate impacts of the newly open Arctic sea. Polar Res 30:15787. https://doi.org/10.3402/polar.v30i0.15787
Peings Y (2019) Ural blocking as a driver of early-winter stratospheric warming. Geophys Res Lett 46:5460-5468. https://doi. org/10.1029/2019GL082097

Screen JA (2017a) Simulated atmospheric response to regional and pan-Arctic sea ice loss. J Clim 30:3945-3962

Screen JA (2017b) The missing northern European winter cooling response to Arctic sea ice loss. Nat Commun 8:14603. https:// doi.org/10.1038/ncomms14603

Screen JA, Simmonds I (2010) Increasing fall-winter energy loss from the Arctic Ocean and its role in Arctic temperature amplification. Geophys Res Lett 37:L16707. https://doi. org/10.1029/2010GL044136

Screen JA, Deser C, Smith DM, Zhang X, Blackport R, Kushner PJ, Oudar T, McCusker KE, Sun L (2018) Consistency and discrepancy in the atmospheric response to Arctic sea-ice loss across climate models. Nat Geosci 11:155-163

Seo KH, Kim KY (2003) Propagation and initiation mechanisms of the Madden-Julian oscillation. J Geophys Res 108:4384. https ://doi.org/10.1029/2002JD002876

Serreze MC, Holland MM, Stroeve J (2007) Perspectives on the Arctic's shrinking sea-ice cover. Science 315:1533-1536

Serreze MC, Barrett AP, Stroeve JC, Kindig DN, Holland MH (2009) The emergence of surface-based Arctic amplification. Cryosphere 3:11-19

Seviour WJM, Mitchell DM, Gray LJ (2013) A practical method to identify displaced and split stratospheric polar vortex events. Geophys Res Lett 40:5268-5273. https://doi.org/10.1002/ grl.50927

Smith KL, Kushner PJ (2012) Linear interference and the initiation of extratropical stratosphere-troposphere interactions. J Geophys Res 117:D13107. https://doi.org/10.1029/2012JD017587

Smith KL, Fletcher CG, Kushner PJ (2010) The role of linear interference in the annular mode response to extratropical surface forcing. J Clim 23:6036-6050

Strong C, Magnusdottir G (2010) Modeled winter sea ice variability and the North Atlantic oscillation: a multi-century perspective. Clim Dyn 34:515-525

Strong C, Magnusdottir G (2011) Dependence of NAO variability on coupling with sea ice. Clim Dyn 36:1681-1689

Sun L, Deser C, Tomas RA (2015) Mechanisms of stratospheric and tropospheric circulation response to projected Arctic sea ice loss. J Clim 28:7824-7845

Waugh DW, Sobel AH, Polvani LM (2017) What is the polar vortex and how does it influence weather? Bull Am Meteorol Soc 98:37-44. https://doi.org/10.1175/BAMS-D-15-00212.1

Wu Y, Smith KL (2014) Response of northern hemisphere midlatitude circulation to Arctic amplification in a simple atmospheric general circulation model. J Clim 29:2041-2058

Yang XY, Yuan X (2014) The early winter sea ice variability under the recent Arctic climate shift. J Clim 27:5092-5110

Yang XY, Yuan X, Ting M (2016) Dynamical link between the Barents-Kara sea ice and the Arctic oscillation. J Clim 29:5103-5122

Zhang J, Tian W, Chipperfield MP, Xie F, Huang J (2016) Persistent shift of the Arctic polar vortex towards the Eurasian continent in recent decades. Nat Clim change 6:1094-1099

Zhang P, Wu W, Smith K (2018) Prolonged effect of the stratospheric pathway in linking Barents-Kara Sea sea ice variability to the midlatitude circulation in a simplified model. Clim Dyn 50:527-539. https://doi.org/10.1007/s00382-017-3624-y

Publisher's Note Springer Nature remains neutral with regard to jurisdictional claims in published maps and institutional affiliations. 